\title{
Study on the Stability of the Geogrids-Reinforced Earth Slope under the Coupling Effect of Rainfall and Earthquake
}

\author{
Xijun Zhang $\mathbb{D},{ }^{1}$ Liang Huang $\left(\mathbb{D},{ }^{2}\right.$ Yujie Hou, ${ }^{1}$ Bo Wang, ${ }^{1}$ Binghan Xue $\mathbb{D},{ }^{1}$ \\ and Mingsheng Shi $\mathbb{I D}^{1}$ \\ ${ }^{1}$ School of Water Conservancy Engineering, Zhengzhou University, Zhengzhou 450001, China \\ ${ }^{2}$ School of Civil Engineering, Zhengzhou University, Zhengzhou 450001, China \\ Correspondence should be addressed to Liang Huang; zzuhuangl@163.com and Binghan Xue; xuebinghan@zzu.edu.cn
}

Received 6 July 2020; Revised 15 September 2020; Accepted 4 October 2020; Published 21 October 2020

Academic Editor: Enrico Conte

Copyright (C) 2020 Xijun Zhang et al. This is an open access article distributed under the Creative Commons Attribution License, which permits unrestricted use, distribution, and reproduction in any medium, provided the original work is properly cited.

This paper focuses on understanding the dynamic response problem of flexible wrapped reinforced Earth slope under the coupling effect of earthquake and rainfall; a numerical calculation model of reinforced Earth slope considering the coupling effect of earthquake and rainfall was established. The dynamic response, pore pressure, and tensile stress distribution of the reinforcement under the rainfall before earthquake, the rainfall after the earthquake, and earthquake-rainfall are studied. The results show that the coupling effect of earthquake and rainfall is an influential factor in the dynamic analysis of reinforced Earth slopes, the analysis of which should be paid attention to and researched in the future. The combination of geogrid and soil effectively improves the deformation of the slope and the overall stability, reduces the secondary disaster of the slope, and provides a reference for the seismic construction design of the reinforced Earth slope.

\section{Introduction}

Slope instability is one of the most common geological disasters in geotechnical engineering. In order to improve the stability of it, many reinforcement methods have been developed including anchors [1-3], soil nailed walls [4-7], and reinforced materials [8-10]. For example, Zhang et al. studied the failure behavior and mechanism of reinforced slopes using soil nail wall under various loading conditions. In this study, a series of centrifuge model tests were conducted on slopes reinforced with a soil nail wall under three types of loading conditions. Test results showed that the soil nailing significantly reduced the deformation of the slope and accordingly delayed the occurrence of the deformation localization [11]. Ling et al. analyzed both static and dynamic characteristics of the reinforced Earth retaining wall. In the centrifugal shaking table tests, the responses of the walls subject to 20 cycles of a sinusoidal wave having a frequency of $2 \mathrm{~Hz}$ and acceleration amplitude of $0.2 \mathrm{~g}$ are compared with the results of the analysis. The acceleration in the backfill, strain in the geogrid layers, and facing deformation are computed and compared to the test results. The comparison of numerical and experimental results showed that the finite element procedure was able to simulate the construction behavior as well as dynamic behavior favorably. The results of analyses confirmed that the length and spacing of reinforcement played an important role in minimizing wall deformations and strains in the reinforcements [9]. The geogrid, another kind of light-weight supporting component, has become more and more popular in slope reinforcement due to its excellent performance in the seismic resistance and the advantage of land-saving [12]. Raw materials currently used to fabricate the geogrids include high-density polyethylene, polypropylene, and glass fiber [13-15]. These materials are readily available, and they are harmless to the environment and cheap, making the geogrids eco-friendly and cost-saving [16]. Along with the rapid development of infrastructure construction, especially in a developing country, the geogrids are playing a more and more critical role in enhancing embankment stability, subgrade bearing capacity, and durability. For example, during the widening process of Zhengshang Road 
(Zhengzhou, China) in 2005, the geogrids were made of high-density polyethylene, which were used for stabilizing the retaining wall and abutment [17]. Another case of the use of geogrids supporting is in reinforcing the Earth road shoulder walls of Chuda No. 1 highway in Yunnan City, China, in 1996, where geogrids made of glass fiber were installed [18]. Besides, in Italy A1 road, geogrids were used for both the base and slope reinforcement [19].

In order to arrange reinforcements more reasonably, the mechanical behavior of the geogrids-reinforced Earth slopes under different geological conditions should be fully understood. Previous studies have pointed out that the instability disasters of slope are usually caused by the weak strength of soil, the overweight of surface soil masses, and the harsh natural environment of earthquake and rainfall [20-25]. Therefore, many studies have been carried out on the mechanical behavior of the geogrids-reinforced Earth slope under different geological conditions [26]. For instance, through shaking table test, Ramakrishnan et al. studied the accelerations, displacement of wrapped reinforced Earth slope, and geotextile-reinforced segmental retaining walls under the seismic loading, and the results have shown that these walls can sustain significant acceleration before lateral movement occurs [27]. The segmental retaining wall was found to sustain approximately two times the critical acceleration of the wrap-faced wall. Geotextilereinforced walls may perform adequately for moderate-tostrong earthquakes (acceleration $<0.5 \mathrm{~g}$ ). In another study, the influences of reinforcement length, reinforcement spacing, soil density, and reinforcement stiffness on the wrapped reinforced soil slope under seismic loading were further investigated [12]. It can be concluded from the results in [12] that reinforcement stiffness is a key parameter dominating the seismic response and deformation mode of a wall, and not reinforcement ultimate tensile strength. Latha et al. focused on understanding the seismic response of geosynthetic-reinforced retaining walls through shaking table tests on models of the modular block and rigid faced reinforced retaining walls. The result was that vertical deformations of the rigid faced walls were not affected by the type of reinforcement. Increasing the quantity of reinforcement resulted in a decrease of settlements for all the model tests. With the inclusion of 3 layers of geogrid, the vertical deformations were reduced by about $60 \%$ in both rigid faced and modular block walls [28].

On the other hand, the influences of rainfall on the mechanical behavior of reinforced Earth slope have also been investigated. Based on the theory of unsaturated seepage, this work researched the effects of rainfall infiltration on the pore pressure and saturation of the widened embankment, the influence of geogrid reinforcement, and packing permeability coefficient on the stability of the embankment. The results show that the safety factor of widening embankment is obviously reduced when considering the influence of rainfall [29]. Geogrid reinforcement can effectively reduce the influence of rainfall infiltration on the stability of widening embankment. Based on the effective stress principle of porous media, a fluid-structural interaction numerical model of stepped reinforced Earth retaining wall under rainfall condition is established, which simulates the velocity distribution in the wall, the pore pressure, and the development of plastic zone. The results show that the change of pore pressure in the wall leads to soil settlement under rainfall, and the change of pore pressure affects effective stress, which in turn affects the shear strength of reinforced Earth structure [30, 31].

These findings have worked as a base for the plan and design of geogrids reinforcement. The combination of earthquake and rainfall is possible [32, 33], especially in southwestern China. Slope is one of the important structures in geotechnical engineering. With the increasing of construction projects in mountainous areas, landslides caused by natural disasters such as earthquakes and rainfall have caused huge economic losses and casualties to the construction and operation of water conservancy, electricity, and transportation projects. In this context, the wrapped reinforced Earth slope has a good application prospect in highway, railway, water conservancy, and other fields because of its simple construction, good earthquake resistance, strong adaptability, beautiful appearance and environmental protection, and good economic effect. However, its working performance is more complicated; in particular the stability of the flexible wrapped reinforced Earth slopes under the coupling effect of earthquake and rainfall is not clear. Therefore, in order to popularize this technology in engineering, it is necessary to study the coupling of earthquake and rainfall. In view of this, this paper intends to study the mechanical behavior of the wrapped reinforced Earth slope under the coupling effect of earthquake and rainfall and reflects the superiority of the wrapped reinforced Earth slope. Stress, displacement, and pore pressure of the reinforced slope under the coeffect of earthquake and rainfall were analyzed. Systematic research on seepage and deformation of reinforced Earth slope is not only a necessary condition for the sustainable development of reinforced Earth slope antiseepage theory but also an important basis for the safe operation of reinforced Earth slope.

\section{Simulation Models and Simulation Procedure}

When the reinforced Earth slope is affected by earthquake and rainfall, the stress field and seepage field are not independent. There is a certain head difference in the medium of the seepage field, the pore water will naturally generate seepage movement under the pressure, and the seepage volume force as external load will be generated. The generation of seepage volume force will inevitably affect the stress balance in the original reinforced earth slope, and then the soil medium displacement and the movement of soil particles will be changed. The void ratio and porosity of the soil must be changed. Because the void ratio and porosity have a certain relationship with the permeability coefficient, the change of void ratio and porosity will also affect the change of the permeability coefficient, and then the seepage field of the soil medium will be changed until it reaches a stable equilibrium state. Therefore, the stress field and seepage field in the reinforced earth slope work together and 
affect each other to form a whole system. This interaction is the coupling relationship [34]. The coupled analysis of the stress field and seepage field of reinforced earth slope is receiving more and more attention in geotechnical engineering. Under the coupling effect, the deformation field, stress field, and pore water pressure of the reinforced Earth slope change more closely to the actual engineering.

\subsection{Influence of Stress Field on Seepage Field. As mentioned} above, the seepage volume force will affect the original stress field balance of the reinforced Earth slope and change the displacement of the soil medium. The movement of soil particles will inevitably change the porosity and void ratio, so the permeability coefficient of the medium will also be changed. The effect of the stress field on the seepage field essentially changes the pores and affects the permeability characteristics of the soil structure.

According to Darcy's Law,

$$
k=k_{0} \frac{\rho g}{\mu}=k_{0} \frac{\gamma_{w}}{\mu}=k_{0} \frac{g}{v},
$$

where $k_{0}$ denotes permeability; $\mu$ denotes absolute viscosity of water; $v$ denotes coefficient of viscosity; $\rho$ denotes density; $g$ denotes gravity; $\gamma_{w}$ denotes volumetric weight of water.

According to equation (1), there are two main factors that affect the soil permeability: one is the fluid properties of the soil, which are represented by $\gamma_{w} / \mu$, and the other is the skeleton properties of the soil represented by the permeability $k_{0}$. The factors that affect the performance index of soil skeleton include specific surface area, particle size, shape, and porosity. Among these factors, the porosity has the greatest influence on the permeability.

The application and experiments in practical engineering show that the permeability coefficient or permeability of soil can be expressed as a function of porosity or void ratio.

The calculation equation of the permeability coefficient of sandy soil is as follows:

$$
k=C_{2} D_{10}^{2.32} C_{n}^{0.6} \frac{e^{3}}{1+e}=C_{2} D_{10}^{2.32} C_{n}^{0.6} \frac{n^{3}}{(1-n)^{2}},
$$

and the calculation equation of the permeability coefficient of normally consolidated cohesive soil is as follows:

$$
k=C_{3} \frac{e^{m}}{1+e}=C_{3} \frac{n^{m}}{(1-n)^{m-1}},
$$

where $D_{10}$ denotes $10 \%$ effective particle size; $C_{\mathrm{n}}$ denotes coefficient of uniformity; $C_{2}, C_{3}$, and $m$ are constants.

When the displacement field and stress field of a slope are changed, the void ratio $e$ and porosity $n$ will change, and the permeability coefficient will be changed, so the seepage field should be recalculated. A function of the stress state $\sigma_{i j}$ can be used to represent the permeability coefficient $k$ :

$$
k=k\left(\sigma_{i j}\right) .
$$

From the above analysis, the mechanism of the effect of the stress field on the seepage field causes the change of the volumetric strain of the soil to affect the change of the permeability coefficient of the soil, thereby affecting the distribution of the seepage field.

2.2. Influence of Seepage Field on Stress Field. In the analysis and calculation of reinforced Earth slopes, the seepage is based on the seepage surface force and the seepage volume force as external loads in the soil medium, which changes the stress field of the reinforced earth slope and further changes the displacement field. Assuming that the head distribution of the homogeneous reinforced Earth slope is $H(x, y, z)$, the seepage water pressure $P$ is

$$
P=\gamma(H-z),
$$

where $y$ denotes volumetric weight; $z$ denotes elevation head.

The volume force of seepage $f$ in the seepage range is expressed as equation (7):

$$
\begin{gathered}
\left\{\begin{array}{c}
f_{x} \\
f_{y} \\
f_{z}
\end{array}\right\}=\left\{\begin{array}{c}
-\frac{\partial P}{\partial x} \\
-\frac{\partial P}{\partial y} \\
-\frac{\partial P}{\partial x}
\end{array}\right\}=\left\{\begin{array}{c}
\gamma \frac{\partial H}{\partial x} \\
\gamma \frac{\partial H}{\partial y} \\
\gamma \frac{\partial H}{\partial x}
\end{array}\right\}, \\
f=\sqrt{f_{x}^{2}+f_{y}^{2}+f_{z}^{2}},
\end{gathered}
$$

where $f_{x}$ denotes component of seepage volume force in $x$ direction; $f_{y}$ denotes component of seepage volume force in $y$-direction; $f_{z}$ denotes component of seepage volume force in $z$-direction.

From the above analysis, it can be seen that the seepage volume force in the seepage field as the external load changes the stress field distribution of the reinforced Earth slope, which also affects the distribution of the displacement field.

2.3. Coupled Analysis of Stress Field and Seepage Field. The basic differential equation of the couple of the stress field and the seepage field is as follows:

$$
\begin{aligned}
& \frac{\partial \sigma_{x}}{\partial x}+\frac{\partial \tau_{x y}}{\partial y}+\frac{\partial \tau_{z x}}{\partial z}+\frac{\partial p}{\partial x}=0 \\
& \frac{\partial \tau_{x y}}{\partial x}+\frac{\partial \sigma_{y}}{\partial y}+\frac{\partial \tau_{z y}}{\partial z}+\frac{\partial p}{\partial y}=0 \\
& \frac{\partial \tau_{x z}}{\partial x}+\frac{\partial \tau_{y z}}{\partial y}+\frac{\partial \sigma_{z}}{\partial z}+\frac{\partial p}{\partial z}=0
\end{aligned}
$$

where $\sigma_{x}, \sigma_{y}, \sigma_{z}, \tau_{x y}, \tau_{y z}, \tau_{x z}$ denote components of effective stress on $x$-axis, $y$-axis, and $z$-axis. $p$ denotes pore pressure.

According to geometric equation (9) and physical equation (10), three displacement components can represent six stress components: 


$$
\left.\begin{array}{c}
\varepsilon_{x}=\frac{\partial u}{\partial x} \\
\varepsilon_{y}=\frac{\partial v}{\partial x} \\
\gamma_{x y}=\frac{\partial v}{\partial x}+\frac{\partial u}{\partial y}
\end{array}\right\},
$$

By substituting equations (9) and (10) into (8) and combining the seepage continuity equation, pore pressure and stress components can be solved.

2.4. Computing Model. The three-dimensional finite difference program FLAC3D was incorporated here to study the stability of reinforced earth slope. In this paper, the Mohr-Coulomb model is selected. Both static and dynamic calculations adopt the Mohr-Coulomb model. The principle of FLAC3D is to solve the dynamic equation. From the algorithm level, the algorithm principle is to solve the equation of motion. The application of Mohr-Coulomb model in soil mechanics can give a more reasonable solution, and the infinite slope model is used to assess the occurrence of landslide due to a prescribed rainfall $[35,36]$. It is a commonly used method to study geological engineering related issues. The model is selected based on the typical widened embankment section of the Wuyi Expressway in Yunnan. Figure 1(a) presents the model simulating the slope enhanced by geogrid. The model includes three parts: the slope, the foundation, and the free filed boundaries. The simulation is divided into 700 zones and 1025 grid points. Both the slope soil and foundation soil are the clay, common soil type in the slope engineering in southwest China $[37,38]$, and the mechanical properties are presented in Table 1 . These parameters were obtained through the geotechnical tests on-site under the temperature of $17^{\circ} \mathrm{C}$ and relative humidity of $68 \%$. The tested specimens were prepared according to the requirement in the specification of soil test (SL237-1999) [39]. In order to simulate the influences of rainfall, in this study, the surface of the reinforced slope is defined as the boundaries, whereas both the bottom and the periphery of the model are impervious [40].

The slope angle is $53^{\circ}$, and both its height and width are $4 \mathrm{~m}$ (Figure 1(a) the model simulating the slope enhanced by geogrids and (b) its geometry size; layouts of (c) the embedded geogrids; and (d) the measuring points that monitor the displacement of the slope). The size of the model in the $x$-direction is $7 \mathrm{~m}$. For the geogrid enhanced slope, the diagram of the embedded geogrids is shown in Figure 1(b) and more details are presented in Figure 1(c). There are 13 layers of wrapped geogrids with a length of $3 \mathrm{~m}$ and a reinforced spacing of $0.3 \mathrm{~m}$. The geogrid unit in the model is simulated by the geogrid structure in the FLAC3D program [41, 42]. The physical and mechanical properties of the geogrid component material (Table 2) were obtained according to the results of the geogrid tensile test and the direct shear test of the reinforced soil interface and refer to the relevant literature and actual engineering situation. The specific values are shown in Table 2.

During the simulation, the internal stress, displacement, and pore pressure of different regions in the slope soil were monitored, and the exact layout of the displacement monitoring points is shown in Figure 1(d). In actual engineering, the geogrids-enhanced slopes are built layer by layer [43]. Thus, $0.5 \mathrm{~m}$ is reserved as the returning section after each layer of edging. Two layers of geogrid are built in the numerical model, and a layer of geogrid is inserted into the vertical plane between the two layers to simplify the simulated wrapped reinforced Earth slope.

During the simulation, the load was applied in the form of a wave and then the table command is used to realize the application of seismic load, respectively, which are used to simulate the earthquake. By setting the seepage boundary of nodes to simulate rainfall, the simulation process lasts for 8 hours.

\section{Results and Discussion}

Three different loading conditions were considered in this study:

(i) Situation-I: rainfall before earthquake.

(ii) Situation-II: rainfall after earthquake.

(iii) Situation-III: earthquake and rainfall.

3.1. Stress Field. Figure 2 shows an image of the maximum principal stress filed of slope. It can be seen that the slope stress gradually increases from top to bottom under the three loading conditions. The tension area appears on the surface and the top of the reinforced Earth slope. Because the slope tends to decline under the action of earthquake and rainfall, regardless of rainfall before earthquake or the simultaneousness of earthquake and rainfall, reinforced Earth slope shows the tensile stress state. The maximum compressive stress is $163 \mathrm{kPa}$ and $159 \mathrm{kPa}$, and the maximum tensile stress is $0.20 \mathrm{kPa}$ and $0.44 \mathrm{kPa}$. However, in the case of rainfall after earthquake, there is no tensile stress area. The reinforced Earth slope is more unstable in the cases of rainfall before earthquake and the simultaneousness of earthquake and rainfall, and the stress state is gradually transformed from compressive stress to tensile stress. The maximum compressive stress is at the bottom of the bedrock under the three loading conditions (Figure 3).

Figure 4 presents the minimum principal stress of reinforced Earth slope under the three loading conditions. From the graph, it can be seen that the compressive stress increases gradually from top to bottom. The maximum compressive stress is at the bottom bedrock, but there is no tensile stress area. 


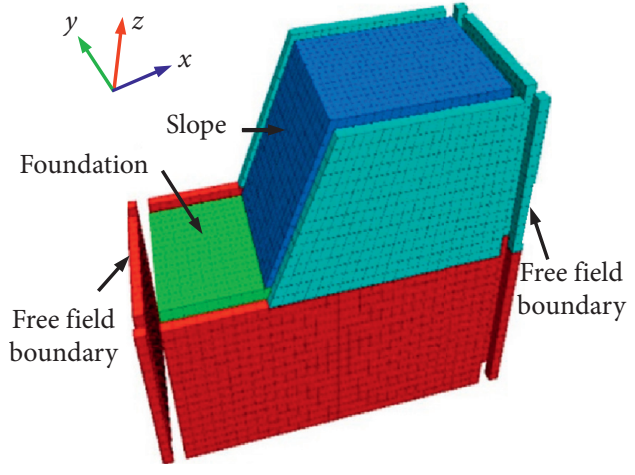

(a)

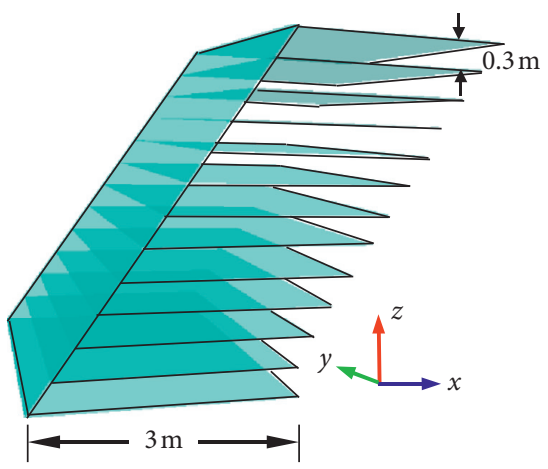

(c)

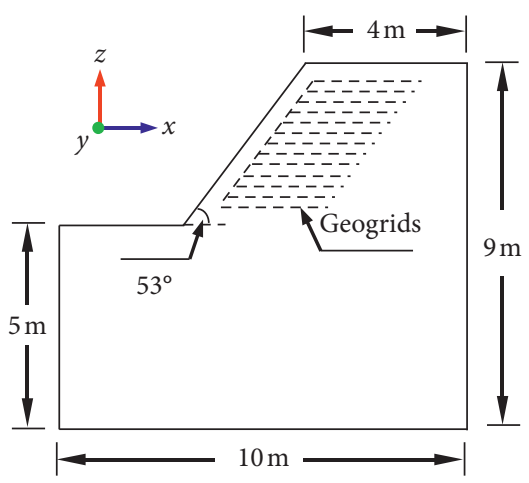

(b)

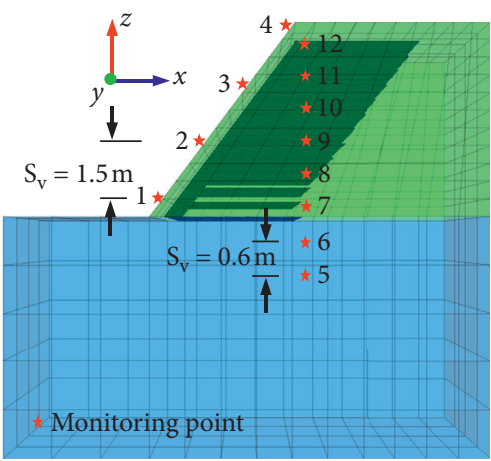

(d)

FIGURE 1: (a) The model simulating the slope enhanced by geogrids and (b) its geometry size; layouts of (c) the embedded geogrids and (d) the measuring points that monitor the displacement of the slope.

TABLe 1: Physical and mechanical properties of soil in the simulation model.

\begin{tabular}{lccccc}
\hline \multirow{2}{*}{ Soil } & \multicolumn{4}{c}{ Properties } & \\
& Volumetric weight, $\gamma(\mathrm{kN} / \mathrm{m} 3)$ & Elastic modulus, E $(\mathrm{GPa})$ & Poisson's ratio, $\mu$ & Cohesion, $\mathrm{c}(\mathrm{kPa})$ & Friction angle, $\varphi\left({ }^{\circ}\right)$ \\
\hline Slope soil & 20.2 & 10 & 0.2 & 38 & 21.4 \\
Foundation soil & 19.0 & 10.7 & 0.3 & 40 & 26 \\
\hline
\end{tabular}

TABle 2: Parameters of geogrid.

Properties

Thickness, (m) Volumetric weight, $\gamma\left(\mathrm{kN} / \mathrm{m}^{3}\right)$ Elastic modulus, E (GPa) Poisson's ratio, $\mu$ Cohesion, c $(\mathrm{kPa}) \quad$ Friction angle, $\varphi\left({ }^{\circ}\right)$

\begin{tabular}{lllllll}
\hline Geogrid & $1.8 \mathrm{e}-3$ & 10 & 26 & 0.33 & 2.3 & 30
\end{tabular}

3.2. Displacement. It can be seen from Figure 5 that the maximum displacement in the case of rainfall before earthquake is $2.53 \mathrm{~cm}$. The maximum displacement in the case of rainfall after earthquake is $2.45 \mathrm{~cm}$, and the maximum displacement in the case of simultaneousness of earthquake and rainfall is $4.52 \mathrm{~cm}$. It can also be seen from Figure 6 that when the earthquake and rainfall act simultaneously, the stability of the reinforced soil slope is the lowest, followed by the rainfall before the earthquake.

Figures 7 and 8 present the contrast curves of horizontal displacement and vertical displacement between reinforced earth slope and natural slope. The maximum settlement occurs at the top of the slope under the coupling effect of earthquake and rainfall. It is about $4.12 \mathrm{~cm}$. With the addition of geogrids, the settlement at the top of the slope was reduced to $1.48 \mathrm{~cm}$, which was decreased by about $64.1 \%$. It can be seen that the horizontal displacement increases gradually from the bottom to the top along the slope height, but the maximum horizontal displacement occurs at a height of $7 \mathrm{~m}$ on the slope. After the geogrid is applied, the slope displacement is reduced by nearly $3 \mathrm{~cm}$, which indicates that geogrid is used to reinforce the slope as a whole.

Figure 9 shows the displacement time curve of different monitoring points under the coupling effect of earthquake and rainfall in the most unstable condition. Figure $1(\mathrm{~d})$ is the monitoring point layout. From the horizontal displacement time history curves of different monitoring points, it can be seen that 


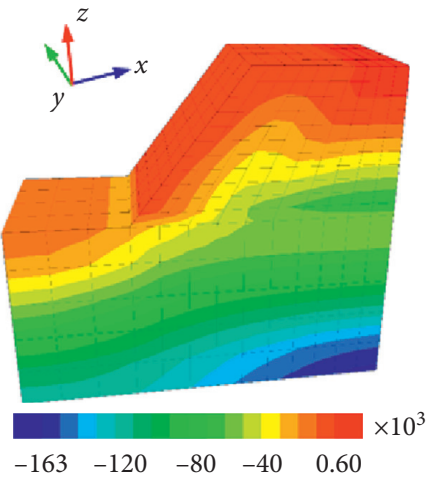

(a)

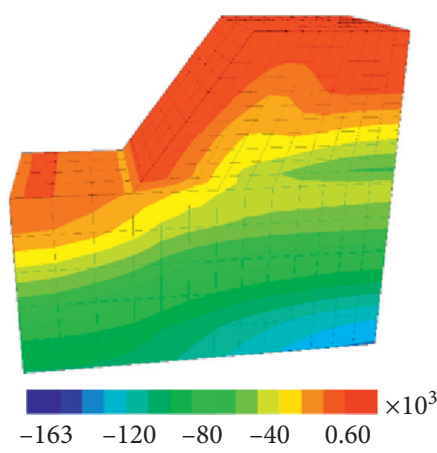

(b)

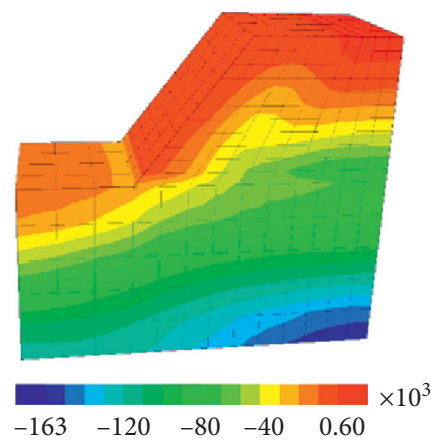

(c)

FIgURe 2: Peak principal stress of reinforced Earth slope. (a) Situation-I. (b) Situation-II. (c) Situation-III (unit: Pa).

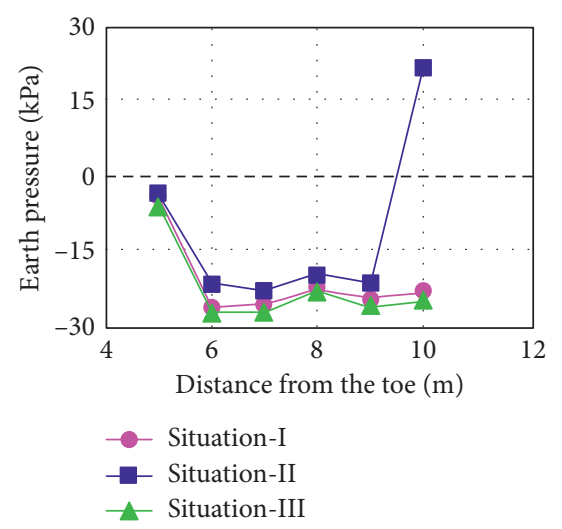

FIGURE 3: Distribution of Earth pressure.

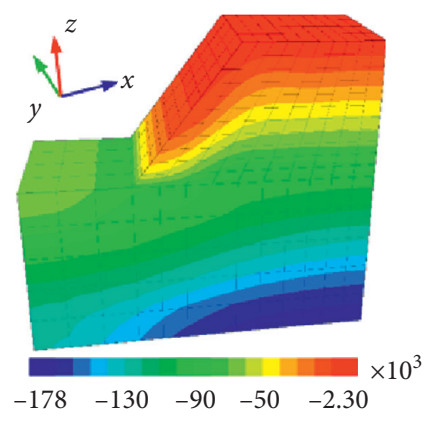

(a)

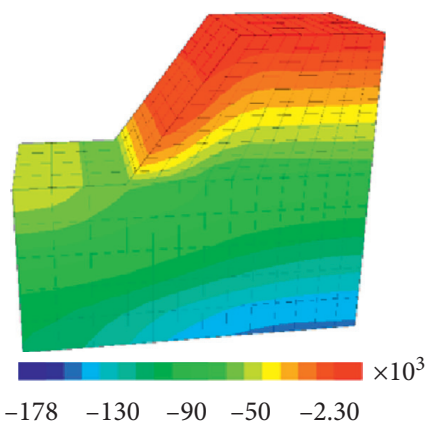

(b)

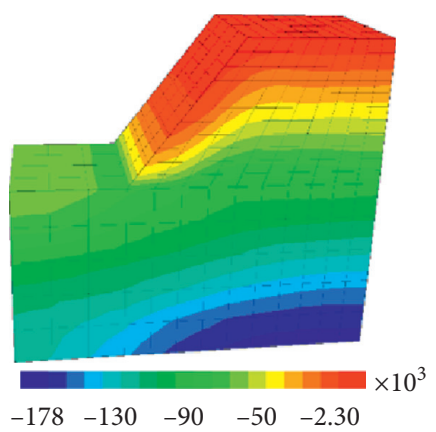

(c)

Figure 4: Minimum principal stress of reinforced Earth slope. (a) Situation-I. (b) Situation-II. (c) Situation-III (unit: Pa).

the displacement law is similar to the loaded seismic wave time history curve, and each height displacement time history curve has a consistent wave form. The moment when the maximum displacement of the slope top monitoring point occurs slightly lags behind the maximum displacement of the slope toe. Because the seismic wave propagates upward, the top response is delayed, which is consistent with the seismic wave applied at the bottom.
From the results of the distribution of 1-4 points along the slope, it can be seen that the peak displacement in the middle of the slope is the largest, and, with the decrease of the slope height, the peak displacement first increases and then decreases. The horizontal displacement changes at 5-12 points of the monitoring points inside the slope also reflecting similar laws. It can be inferred from Figure 9 that the lateral displacement of the 


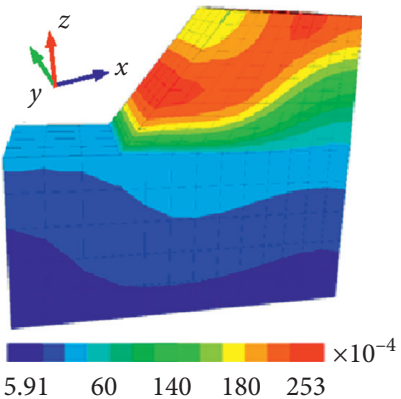

(a)

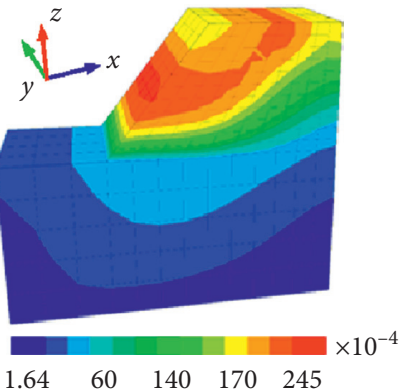

(b)

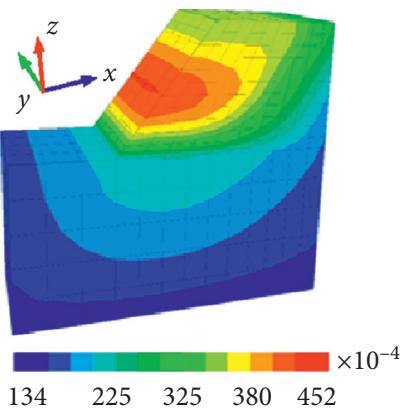

(c)

Figure 5: Total displacement of reinforced Earth slope. (a) Situation-I. (b) Situation-II. (c) Situation-III (unit: m).

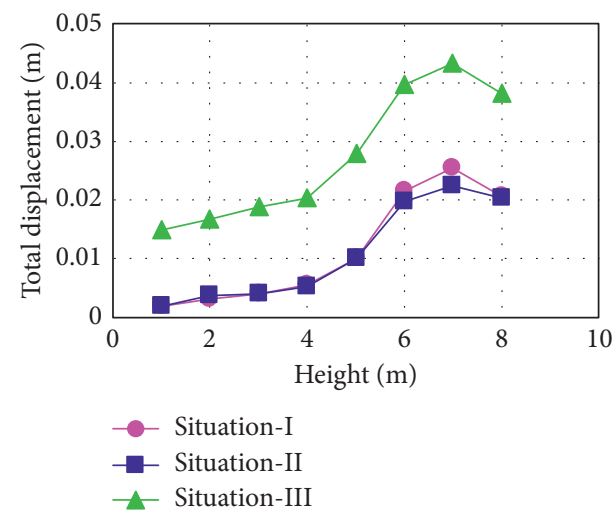

FIGURE 6: Relationship between total displacement and slope height.

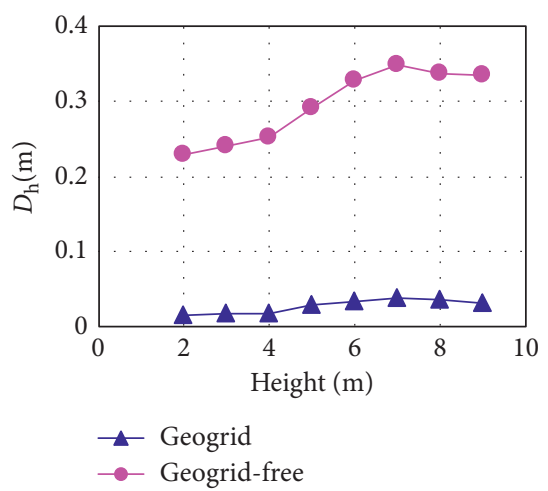

Figure 7: Horizontal displacement of slope.

slope is the largest, and the large deformation of the slope causes the first crack. The serious situation leads to the secondary disaster of the landslide.

3.3. Shear Strain Increment. Figure 10 shows the incremental strain distribution at different loading conditions. It can be seen from Figure 10 that the shear strain increment is the largest under the simultaneous action of earthquake and rainfall. The maximum shear strain appears in the middle and lower parts of the reinforced earth slope. This is the most dangerous location for the reinforced earth slope. The slope will slide from there,

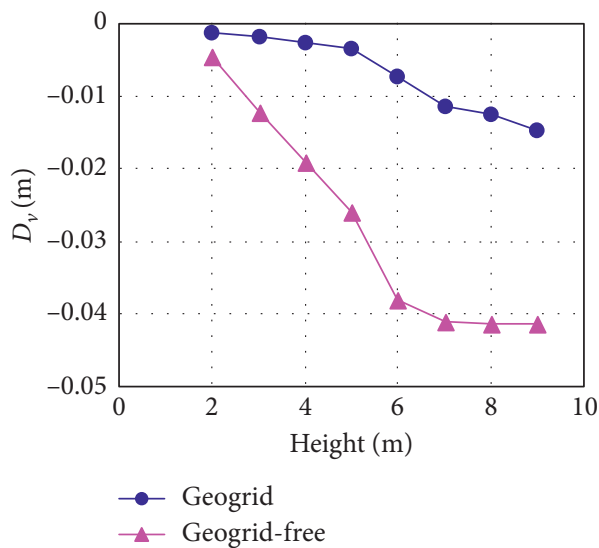

Figure 8: Vertical displacement of slope.

and the shear strain increment will gradually develop upward and downward along the maximum area. Finally, a cambered surface is formed from the toes to the top of the slope. This area is the most vulnerable to shear failure, and it is also the most dangerous sliding surface of the reinforced earth slope.

3.4. Pore Pressure. The pore pressure value decreases first and then increases from the top to the bottom of the slope. The top of the slope firstly contacts rainwater during the rainfall, and the upper rainwater continuously infiltrates into the slope. However, the dynamic load increases the pore pressure of slope. It can be seen from Figure 11 that the lower part of the slope is gradually saturated, and the upper part is in an unsaturated state. The pore water pressure of the lower soil is higher than that of the upper soil.

3.5. Tensile Stress of Geogrid. The action mechanism of the reinforced earth slopes is mainly the friction between the reinforcement and the soil, the restriction of the grid holes on the soil, and the resistance of the grid ribs. In short, it is the interaction between the reinforcement and the soil. All three forms can restrain the lateral displacement of soil particles, thereby increasing soil stability. Reinforcement is an important part of the reinforced earth slope, and its mechanical characteristics are obviously the emphasis of research. As shown in Figure 12, the tensile stress of the 

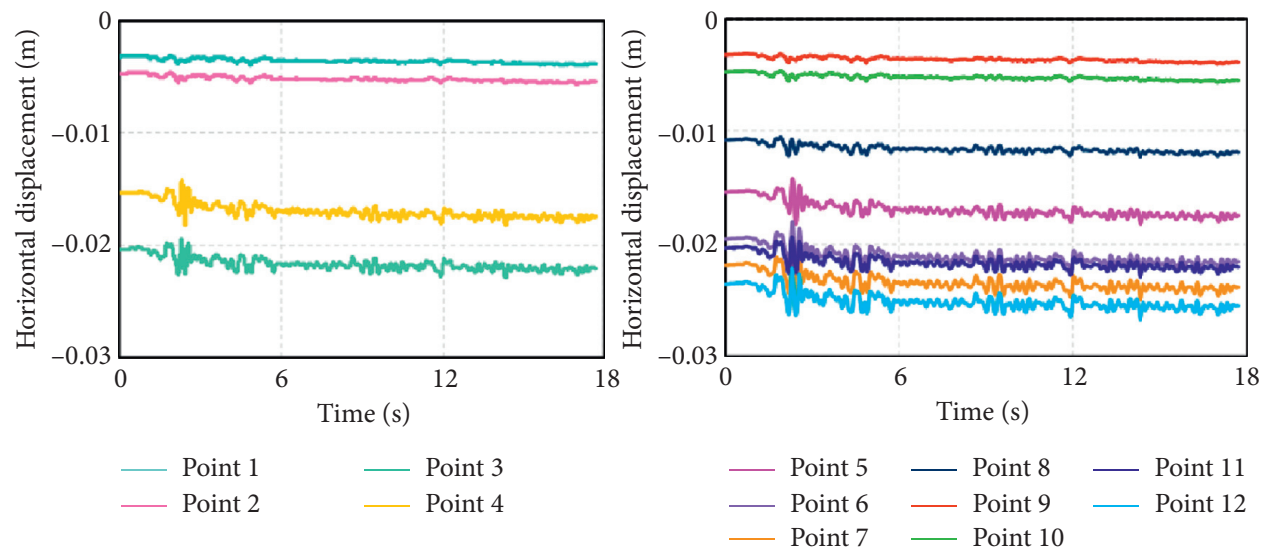

FIgURE 9: Horizontal displacement histories curve.

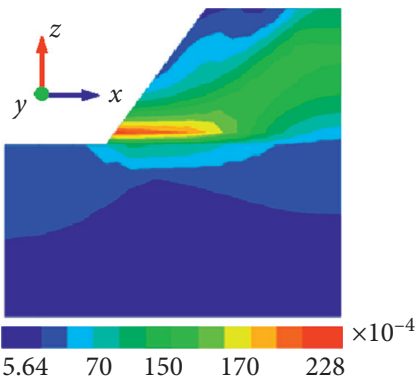

(a)

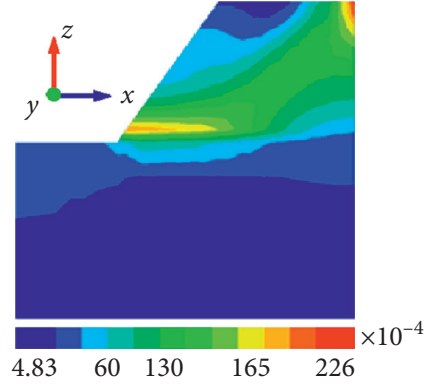

(b)

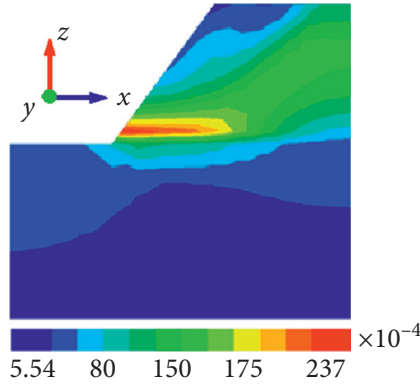

(c)

FIGURE 10: Peak shear strain increment of reinforced earth slope. (a) Situation-I. (b) Situation-II. (c) Situation-III (unit: Pa).

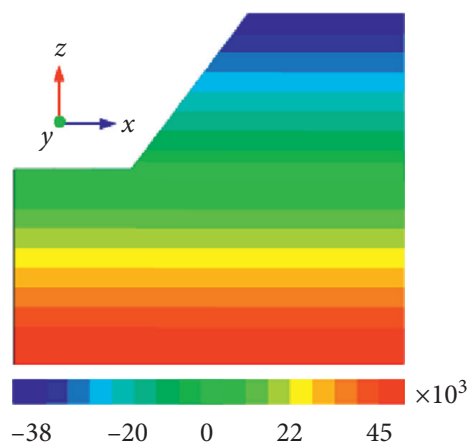

(a)

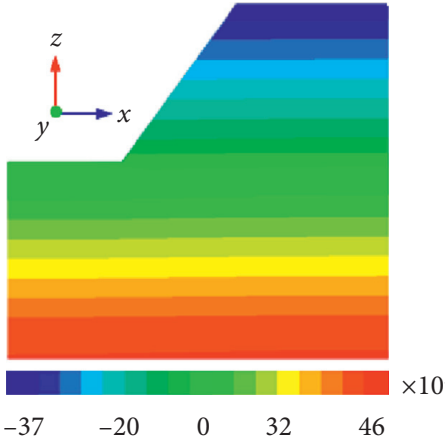

(b)

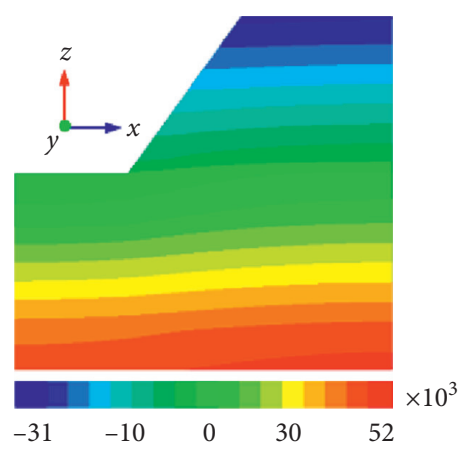

(c)

FIgURE 11: Pore pressure of reinforced earth slope. (a) Situation-I. (b) Situation-II. (c) Situation-III (unit: Pa).

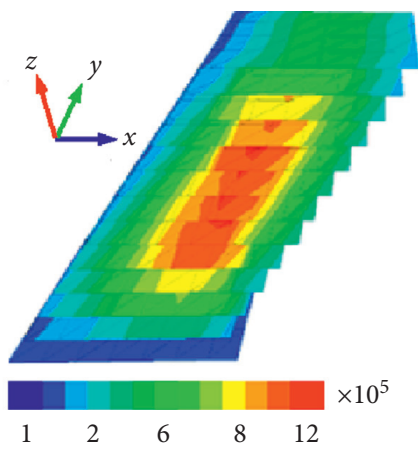

(a)

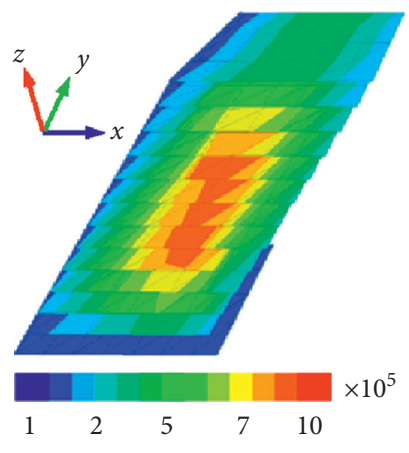

(b)

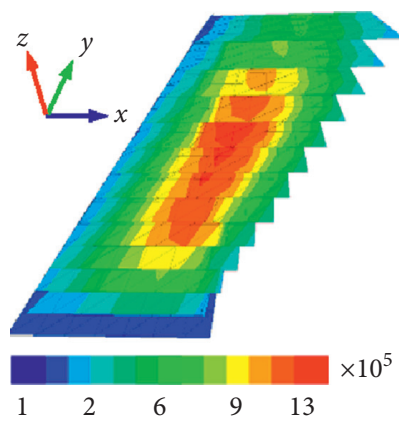

(c)

FIgURe 12: Peak principal stress of geogrid. (a) Situation-I. (b) Situation-II. (c) Situation-III (unit: Pa). 


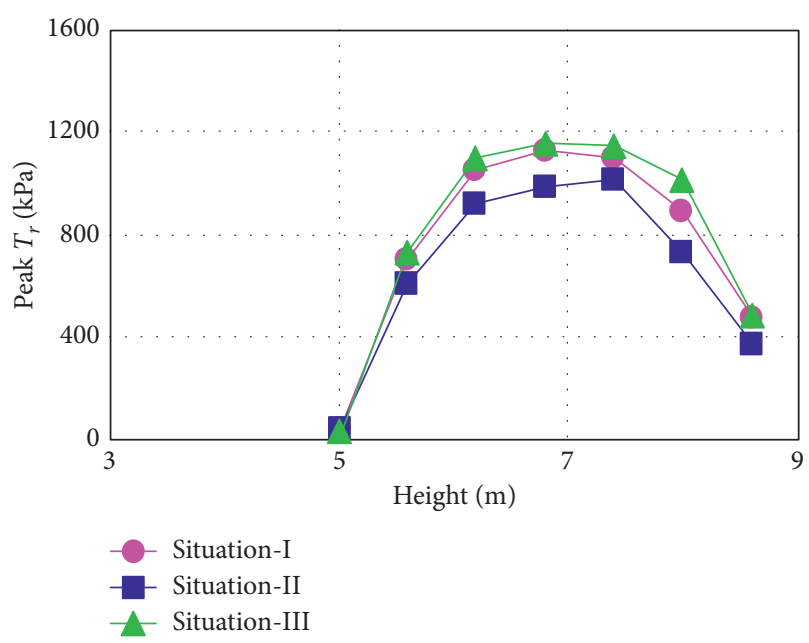

FIGURE 13: Relationship between the peak tensile stress of reinforced materials and the height of reinforced earth slope.

geogrid first increases and then decreases with the increases of height, and an elliptical high-stress zone is formed in the section of the slope. The peak principal stress of the geogrid is the largest under the coupling effect of earthquake and rainfall, followed by the rainfall before earthquake. Figure 13 is the relationship between the axial tensile stress of the geogrid (peak $T_{\mathrm{r}}$ ) and the slope height. According to the variation law of the curve, the axial stress of the reinforcement first increases and then decreases from the bottom to the top of the geogrid, and the peak value appears in the middle of the reinforcement. The horizontal axial tensile stress distribution of the geogrid is characterized by "large in the middle and small in both ends."

Through numerical simulation, the distribution of stress field, displacement field, shear strain increment, pore pressure, and tensile stress of reinforced earth slope in the cases of rainfall before earthquake, rainfall after earthquake, and the coupling effect of earthquake-rainfall are obtained. The strength reduction method is used to solve the safety factor of the wrapped reinforced earth slope (see equations (11) and (12)). According to the calculation of solving FOS in the software, the safety factors of the three loading conditions are obtained, as shown in Table 3.

$$
\begin{aligned}
& c_{F}=\frac{c}{F_{\text {trial }}}, \\
& \phi_{F}=\tan ^{-1} \frac{\tan \phi}{F_{\text {trial }}},
\end{aligned}
$$

where $c_{F}$ denotes cohesion after reduction, $\mathrm{c}$ denotes cohesion, $\phi$ denotes internal friction angle, $\phi_{F}$ denotes internal friction angle after reduction, and $F_{\text {trial }}$ denotes reduction coefficient.

It can be seen from Table 3 that the safety factor of the wrapped reinforced earth slope under the rainfall after earthquake is 1.32 . The safety factor of the wrapped reinforced earth slope under the rainfall before earthquake is 1.20 , which is relatively low. The safety factor is 1.08 under
TABLE 3: Factors of safety under different working conditions.

\begin{tabular}{lccc}
\hline & $\begin{array}{c}\text { Rainfall after } \\
\text { earthquake }\end{array}$ & $\begin{array}{c}\text { Rainfall before } \\
\text { earthquake }\end{array}$ & $\begin{array}{c}\text { Earthquake and } \\
\text { rainfall }\end{array}$ \\
\hline $\begin{array}{l}\text { Factors of } \\
\text { safety }\end{array}$ & 1.32 & 1.20 & 1.08 \\
\hline
\end{tabular}

the simultaneousness of earthquake and rainfall. It is indicated that the wrapped reinforced earth slope is stable under the three conditions, but the coupling effect of earthquake and rainfall is the worst. It is in a critical state.

In the case of the coupling effect of the rainfall before earthquake, it can be known from the previous numerical simulation results that this coupling has a great influence on the stability of the reinforced earth slope, mainly because the rainfall will increase the volumetric weight of the reinforced earth slope, and the shear stress of the slope will increase. Applying seismic loads on this basis will further increase the shear stress and reduce the stability of the reinforced earth slope. The water content of rainfall infiltration increases on the slope. The instantaneous pore pressure generated by the seismic force and the pore pressure generated by seepage flow are superimposed, and matric suction is reduced. The strength and stability of reinforced earth slope will decrease with the decrease of matrix suction.

Under the coupling effect of the rainfall after earthquake, the permeability of the reinforced earth slope increases after the earthquake, and the earthquake will also cause plastic deformation of the reinforced earth slope and decrease its strength. After rainfall, the soil structure becomes looser and the negative pore pressure on the surface of the slope is larger. This will accelerate the infiltration of rainfall into the slope, resulting in obvious load-increasing effect, which will reduce the stability of the reinforced earth slope.

Under the coupling effect of earthquake and rainfall, the seismic action increases the crack of the reinforced earth slope. The rainfall effect increases the volumetric weight of the reinforced earth slope. Both of them accelerated the failure of reinforced earth slope. According to the previous numerical analysis, the influence of the rainfall before earthquake is greater than the impact of the rainfall after earthquake, but both are less than the simultaneousness of earthquake and rainfall.

\section{Conclusions}

Through numerical analysis, the dynamic response and the change of seepage field of the reinforced earth slope for the cases of rainfall before earthquake, rainfall after earthquake, and rainfall and earthquake are obtained. The conclusions can be summarized as follows:

(1) Reinforced earth slope is unstable in the cases of rainfall before earthquake and the simultaneousness earthquake and rainfall. The stress state is gradually transformed from compressive stress to tensile stress, and the tensile stress increases under the coupling effect of earthquake and rainfall. 
(2) The peak tensile stress of the steel bar is the smallest under the condition of an earthquake before rainfall. With the increase of slope height, the tensile stress of geogrid increases first and then decreases, and an elliptical high-stress zone is formed in the section of the slope.

(3) Under the coupling effect of rainfall before earthquake, the water content of rainfall infiltration increases on the slope. The instantaneous pore pressure generated by the seismic force and the pore pressure generated by seepage flow are superimposed, and the strength is reduced.

(4) In case of rainfall after earthquake, rainfall more easily penetrated into the slope. Pore pressure decreases with the increase of surface soil moisture

(5) Although this paper has actively explored and studied reinforced earth slopes and obtained some valuable results for engineering practice, due to the complexity of the factors affecting the mechanical properties of reinforced earth slopes, the use of backfill soil has not yet considered the layering of the anisotropic soil layers of soil materials, and there will be different soil materials in actual projects.

\section{Data Availability}

The (figures and tables) data used to support the findings of this study are included within the article. In addition, the finite element models are available from the corresponding author upon request.

\section{Conflicts of Interest}

The authors declare that the work described has not been published before, that it is not under consideration for publication anywhere else, that its publication has been approved by all coauthors, and that there are no conflicts of interest regarding the publication of this article.

\section{Acknowledgments}

The study was supported by National Key Research and Development Program of China (2017YFC0405002) and the National Natural Science Foundation of China (Grant no. 51908515).

\section{References}

[1] M. Yan, Y. Xia, T. Liu, and V. M. Bowa, "Limit analysis under seismic conditions of a slope reinforced with prestressed anchor cables," Computers and Geotechnics, vol. 108, pp. 226-233, 2019.

[2] D.-P. Deng, L. Li, and L.-H. Zhao, "Stability analysis of slopes reinforced with anchor cables and optimal design of anchor cable parameters," European Journal of Environmental and Civil Engineering, pp. 1-16, 2019.

[3] E. Conte, A. Troncone, and M. Vena, "A method for the design of embedded cantilever retaining walls under static and seismic loading," Géotechnique, vol. 67, pp. 1-9, 2017.
[4] J. H. Dong and Y. P. Zhu, "Stability analysis of slope supported by soil nailing retaining wall under earthquake," China Journal of Highway \& Transport, vol. 21, pp. 20-25, 2008.

[5] Y. P. Zhu and T. Z. Ma, "Stability model of slope supported by composite soil nailing wall and its application under earthquake," Journal of Lanzhou University of Technology, vol. 35, 2009.

[6] P. Rawat and K. Chatterjee, "Seismic stability analysis of soil slopes using soil nails," Geotechnical Earthquake Engineering and Soil Dynamics, pp. 79-87, 2018.

[7] L. Wang, G. Zhang, and J.-M. Zhang, "Nail reinforcement mechanism of cohesive soil slopes under earthquake conditions," Soils and Foundations, vol. 50, no. 4, pp. 459-469, 2010.

[8] K. Z. Z. Lee, N. Y. Chang, and H. Y. Ko, "Numerical simulation of geosynthetic-reinforced soil walls under seismic shaking," Geotextiles and Geomembranes, vol. 28, no. 4, pp. 317-334, 2010.

[9] H. I. Ling, S. Yang, D. Leshchinsky, H. Liu, and C. Burke, "Finite-element simulations of full-scale modular-block reinforced soil retaining walls under earthquake loading," Journal of Engineering Mechanics, vol. 136, no. 5, pp. 653-661, 2010.

[10] H. I. Ling, H. Liu, V. N. Kaliakin, and D. Leshchinsky, "Analyzing dynamic behavior of geosynthetic-reinforced soil retaining walls," Journal of Engineering Mechanics, vol. 130, no. 8, pp. 911-920, 2004.

[11] G. Zhang, J. Cao, and L. Wang, "Failure behavior and mechanism of slopes reinforced using soil nail wall under various loading conditions," Soils and Foundations, vol. 54, no. 6, pp. 1175-1187, 2014.

[12] M. Sabermahani, A. Ghalandarzadeh, and A. Fakher, "Experimental study on seismic deformation modes of reinforced-soil walls," Geotextiles and Geomembranes, vol. 27, no. 2, pp. 121-136, 2009.

[13] Y. Gong, Y. He, C. Han, Y. Shen, and G. Tan, "Stability analysis of soil embankment slope reinforced with polypropylene fiber under freeze-thaw cycles," Advances in Materials Science and Engineering, vol. 2019, pp. 1-10, Article ID 5725708, 2019.

[14] Y. Xu, Y. Bai, P. Fang, S. Yuan, and C. Liu, "Structural analysis of fibreglass reinforced bonded flexible pipe subjected to tension," Ships and Offshore Structures, vol. 14, no. 7, pp. 777-787, 2019.

[15] I. M. Arsenie, C. Chazallon, J. Duchez, and S. Mouhoubi, "Modelling of the fatigue damage of a geogrid-reinforced asphalt concrete," Road Materials \& Pavement Design, vol. 18, no. 1, pp. 1-13, 2016.

[16] H. Hargitai, I. Rácz, and R. D. Anandjiwala, "Development of HEMP fiber reinforced polypropylene composites," Journal of Thermoplastic Composite Materials, vol. 21, no. 2, pp. 165-174, 2008.

[17] Y. T. Yang, "Talking about the application of geogrid reinforced soil in the embankment slope engineering of Zhengshang road in Zhengzhou City," Henan Building Materials, no. 3, pp. 5-7, 2014.

[18] T. Q. Ling, "Research on high reinforced earth retaining wall design methods in highway engineering," China Journal of Highway \& Transport, vol. 13, pp. 13-15, 2000.

[19] P. Rimoldi and F. Talone, "Base and slope reinforcement of very tall reinforced embankments for the A1 highway in Italy," in Proceedings of the 9th International Conference on Geosynthetics: Advanced Solutions for a Challenging World, ICG, pp. 1623-1628, Guarujá, Brazil, 2010.

[20] P. Rui, B. Xu, Z. DeGao, and K. XianJing, "Seismic performance assessment of high CFRDs based on fragility analysis," 
Science China (Technological Sciences), vol. 62, no. 4, pp. 635-648, 2019.

[21] Y. Wang, Y. Gao, B. Li, L. Guo, Y. Cai, and A. H. Mahfouz, "Influence of initial state and intermediate principal stress on undrained behavior of soft clay during pure principal stress rotation," Acta Geotechnica, vol. 14, no. 5, pp. 1379-1401, 2019.

[22] J. Liang, S. He, N. Li, W. Wang, and K. Yao, "Stability of reinforced retaining wall under seismic loads," Applied Sciences, vol. 9, no. 11, p. 2175, 2019.

[23] B. Xu, Y. Zhou, and R. Pang, "Seismic stability reliability assessment of nuclear power plant's bank revetment considering unreinforced and reinforced situations," Annals of Nuclear Energy, vol. 136, Article ID 107025, 2020.

[24] Y. Wang, Y. Wan, M. Liu, C. Guo, C. Zeng, and D. Wu, "Undrained multi-dimensional deformation behavior and degradation of natural soft marine clay from HCA experiments," Soils and Foundations, vol. 60, no. 1, pp. 103-114, 2020.

[25] P. Ni, G. Mei, and Y. Zhao, "Influence of raised groundwater level on the stability of unsaturated soil slopes," International Journal of Geomechanics, vol. 18, pp. 4018161-4018168, 2018.

[26] L. Tang, S. Cong, X. Ling, and N. Ju, "The boundary conditions for simulations of a shake-table experiment on the seismic response of 3D slope," Earthquake Engineering \& Engineering Vibration, vol. 16, no. 1, pp. 23-32, 2017.

[27] S. Ramakrishnan, M. Budhu, and A. Britto, "Laboratory seismic tests of geotextile wrap-faced and geotextile-reinforced segmental retaining walls," Geosynthetics International, vol. 5, no. 1-2, pp. 55-71, 1998.

[28] G. M. Latha and P. Santhanakumar, "Seismic response of reduced-scale modular block and rigid faced reinforced walls through shaking table tests," Geotextiles and Geomembranes, vol. 43, no. 4, pp. 307-316, 2015.

[29] J. J. Zheng, H. Yu, Z. S. Guo, and W. Z. Cao, "Numerical analysis of stability of widened embankment under rainfall conditions," Journal of Hunan University (Natural Sciences), vol. 44, pp. 150-155, 2017.

[30] F. M. Deng, G. C. He, and F. Yu, "Analysis of influence of rainfall infiltration on stability of stepped reinforced earth retaining wall," Highway, no. 2, pp. 28-32, 2011.

[31] P. Pei, Y. Zhao, P. Ni, and G. Mei, "A protective measure for expansive soil slopes based on moisture content control," Engineering Geology, vol. 269, Article ID 105527, 2020.

[32] B. Tiwari, B. Ajmera, and D. Tran, "Influence of postearthquake rainfall on the stability of clay slopes-IPL-192," in World Landslide Forum 4Springer, Berlin, Germany, 2017.

[33] M. A. Biot, "Mechanics of deformation and acoustic propagation in porous media," Journal of Applied Physics, vol. 33, no. 4, pp. 1482-1498, 1962.

[34] H.-z. Qiu, J.-m Kong, R.-c Wang, Y. Cui, and S.-w Huang, "Response mechanism of post-earthquake slopes under heavy rainfall," Journal of Seismology, vol. 21, no. 4, pp. 869-884, 2017.

[35] E. Conte and A. Troncone, "Analytical method for predicting the mobility of slow-moving landslides owing to groundwater fluctuations," Journal of Geotechnical and Geoenvironmental Engineering, vol. 137, no. 8, pp. 777-784, 2011.

[36] A. Troncone and E. Conte, "A method for the analysis of soil slips triggered by rainfall,” Géotechnique, vol. 62, pp. 187-192, 2012.

[37] J. S. Wang, Y. M. Li, G. X. Wang, and X. P. Zhao, "Experimental study on engineering properties of red clay in
Southwest Mountainous Area," Subgrade Engineering, vol. 6, pp. 97-101, 2013.

[38] Y. H. Qin, X. Xin, Y. R. Li, and Y. Deng, "Calculation and analysis of settlement deformation stress of underground foundation of hangjiangyan hydropower station in Yunnan province," Heilongjiang Water Resources, vol. 2, pp. 5-10, 2016.

[39] People's Republic of China Industry Standard. SL237-1999, Specification of Soil Test, China Water\&Power Press, Beijing, China, 1999.

[40] K.-H. Yang, J. N. Thuo, J.-W. Chen, and C.-N. Liu, "Failure investigation of a geosynthetic reinforced soil slope subjected to rainfall," Geosynthetics International, vol. 26, no. 1, pp. 42-65, 2018.

[41] Y. M. Chen and D. P. Xu, FLAC $\backslash F L A C 3 D$ Foundation and Engineering Examples, China Water\&Power Press, Beijing, China, 2013.

[42] Z. Zhan and S. Qi, "Numerical study on dynamic response of a horizontal layered-structure rock slope under a normally incident sv wave," Applied Sciences, vol. 7, no. 7, p. 716, 2017.

[43] E. Bourgeois, L. Soyez, and A. Le Kouby, "Experimental and numerical study of the behavior of a reinforced-earth wall subjected to a local load," Computers and Geotechnics, vol. 38, no. 4 , pp. 515-525, 2011. 